Supplement of Earth Syst. Dynam. Discuss., 6, 1277-1308, 2015

http://www.earth-syst-dynam-discuss.net/6/1277/2015/

doi:10.5194/esdd-6-1277-2015-supplement

(C) Author(s) 2015. CC Attribution 3.0 License.

(c) (1)

$\begin{array}{r}\text { Earth System } \\ \text { Dynamics } \\ \hline \text { Discussions }\end{array}$

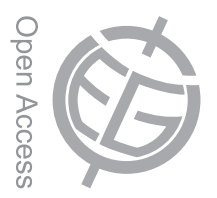

Supplement of

\title{
Climate model emulation in an integrated assessment framework: a case study for mitigation policies in the electricity sector
}

\section{A. M. Foley et al.}

Correspondence to: A. M. Foley (amf62@cam.ac.uk)

The copyright of individual parts of the supplement might differ from the CC-BY 3.0 licence. 


\section{Supplement}

This research uses simulations of anthropogenic $\mathrm{CO}_{2}$ emissions generated by the Energy-EconomyEnvironment Model at the Global level (E3MG) coupled to the Future Technology Transitions: Power (FTT:Power) model. E3MG is a top-down non-equilibrium macroeconometric model, while FTT:Power is a bottom-up model of technology substitution dynamics in the power sector. Here we describe those models in further detail.

\section{E3MG/E3ME}

The E3MG and E3ME variants are dynamic simulation models of the global economy. E3ME and E3MG have different regional and sectoral specifications, however they use the same econometric equations. Therefore we refer the reader to the most recent version of the E3ME technical manual for further details (Cambridge Econometrics, 2014).

The model is based on a 'new economics' non-equilibrium approach with post-Keynesian foundations (Barker and Scrieciu, 2010). Economic activity undertaken by individuals, households, firms, government and other groups has effects, both positive and negative, on all groups after a time lag. Effects are transmitted through the environment, economy and price systems, global transport and information networks. E3MG aims to represent these interdependencies by including the relevant linkages between different parts of the economic and energy systems (Fig. 1).

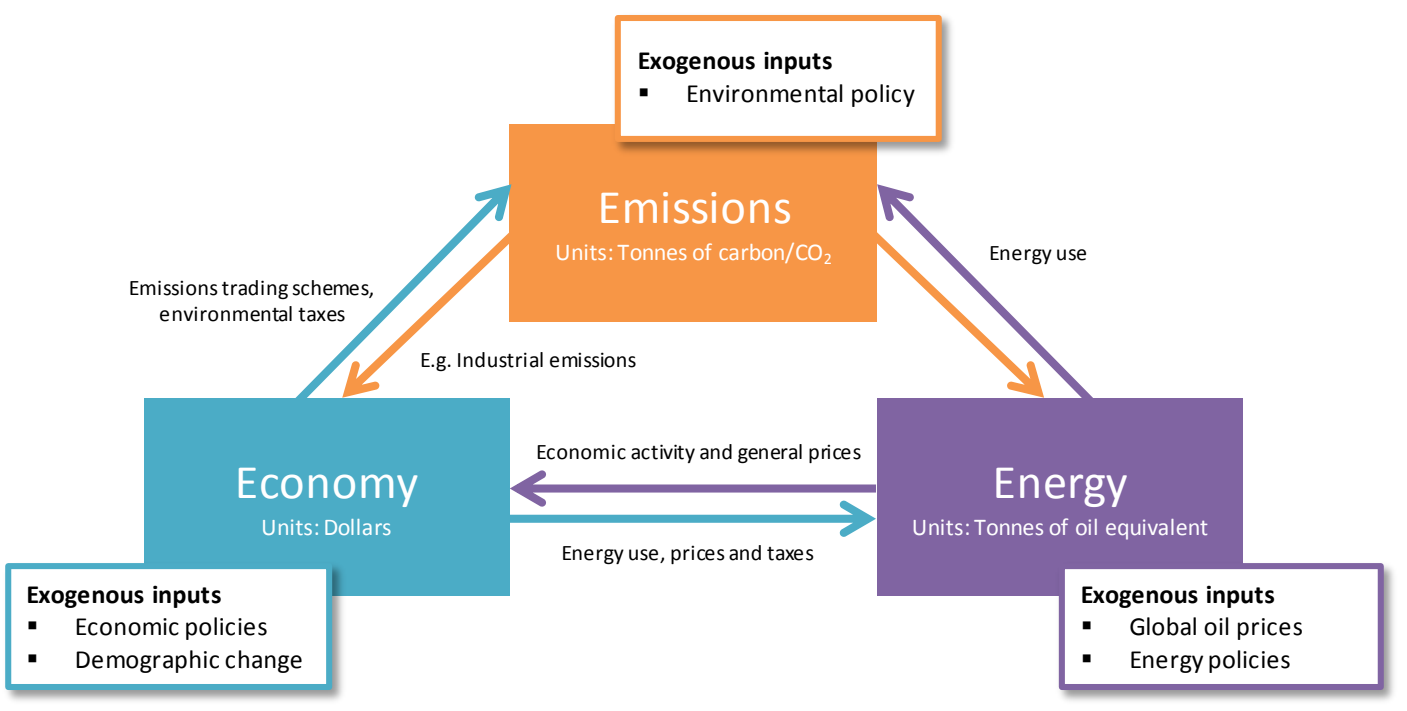

Figure S1. Overall structure of E3MG. Exogenous factors are shown on the outside edge of the chart as inputs into each component (adapted from Cambridge Econometrics, 2014).

E3MG contains 21 world regions (includes explicit treatment of the US, Japan, India, China, Australia, Mexico, Brazil, Russia, Indonesia and the four largest European Union economies), 43 industrial sectors, 28 consumer spending categories, 12 different fuel types, and 14 atmospheric emissions. Sectors are connected using an accounting framework of input-output relationships, expressing intra-industry flows of goods and investments. As such, the model is demand-led and supply-constrained.

Behavioural relationships in E3MG are estimated by econometric methods (namely, using cointegration and error-correction). The model is based on 22 econometric equations evaluated against a historical database that covers the period 1970-2012. Each equation is disaggregated by region and sector, resulting in a set of just over 13,000 equations, which are solved with a yearly time step. The main data sources in Europe are Eurostat and the AMECO database, with the Organisation for Economic Co-operation and Development (OECD), Asian Development Bank and national sources 
used for other countries. Energy and emissions data are taken from the International Energy Agency (IEA) database and the Emissions Database for Global Atmospheric Research (EDGAR).

Although it must be noted that parameters based on historical data may not be appropriate for modelling to the end of this century, this econometric specification gives the model a strong empirical foundation. Furthermore, this empirical basis means that the model is not reliant on many of the assumptions common to Computable General Equilibrium (CGE) models (such as perfect competition in all markets, or no involuntary unemployment).

For the calculation of emissions, a system of fixed coefficients is used. For $\mathrm{CO}_{2}$, these coefficients relate emission levels to the consumption of each fossil fuel by each sector and they are held constant in the model over the projection period. For example, if the power sector's coal consumption increases by $10 \%$ then the sector's $\mathrm{CO}_{2}$ emissions from coal will also increase by $10 \%$.

For non- $\mathrm{CO}_{2}$ emissions and non-energy $\mathrm{CO}_{2}$ emissions, relationships are formed based on the closest relevant model variable. For example, process emissions from the cement sector are linked to the real economic production of that sector.

The power sector in E3MG is represented using FTT:Power, which is fully integrated within E3MG (and E3ME), so that the two models interact dynamically. FTT:Power takes electricity demand from E3MG and feeds back, amongst other variables, energy consumption results for the power sector. As described above, E3MG applies fixed coefficients to the fuel consumption results to estimate emissions levels.

\section{FTT:Power}

The FTT:Power model represents gradual technological substitution processes. Here it is used for generating scenarios of future technology and energy use, in order to calculate future greenhouse gas emission. It projects the future evolution of the power sector in 21 regions, for 24 power technologies, and is introduced in Mercure (2012).

The model is constructed around a family of non-linear differential equations that calculate the substitution dynamics between technologies according to investor choices. This family of equations is sometimes called 'Replicator Dynamics' in evolutionary economics, or 'Lotka-Volterra' in mathematical ecology. It reproduces the classic S-shaped curve, where initial diffusion is slow, then progresses fast, before saturating at high levels of market penetration.

Technology switching is modelled using a pairwise comparison of costs based on a binary logit structure. For an arbitrary number of technologies, exchanges between market shares of technology $i\left(S_{i}\right)$ and $j\left(S_{j}\right)$ can be written as:

$$
\Delta S_{i j}=S_{i} S_{j}\left(A_{i j} F_{i}\left(\Delta C_{i j}\right)-A_{j i} F_{j}\left(-\Delta C_{i j}\right)\right) \Delta t
$$

Here, $A_{i j}$ is a matrix of substitution frequencies for every possible pair of technologies. $F_{i j}\left(\Delta C_{i j}\right) F_{i}\left(\Delta C_{i j}\right)$ is a binary logit cumulative probability function expressing investor/consumer preference for technology $i$ over $j$, which is dependent on the levelized cost of electricity (LCOE) of both options (i.e. the per-kilowatt-hour cost of building and operating that type of energy generation plant over its life cycle). Note that even if one technology is on average less expensive than another, there may be individual cases where the reverse is true; the probabilistic approach captures this variation.

Investor/consumer preference therefore changes as LCOE of different technologies changes. FTT includes cost reductions due to technological learning (e.g. improvements in production methods), 
which depend directly on the number of units produced. The change in the cost of production, $C_{i}$, associated with technology $i$ is:

$$
\Delta C_{i}=-b_{i} \frac{C_{i}}{W_{i}} \Delta W_{i}
$$

Here, $b_{i}=\ln \left(1-a_{i}\right) / \ln (2)$, where $a_{i}$ is the progress ratio for technology $i$; that is, the corresponding percentage change in cost due to a doubling of cumulative capacity (Berglund and Soderholm, 2006). $W_{i}$ is the total number of units of that technology that have ever been sold Values for the initial cost of different technologies, and progress rates from which values of $b_{i}$ are calculated, are based on an ensemble of reports (IEA, 2000; OECD/NEA , 2010; McDonald and Schrattenholzer, 2001). Diffusion or decline of a particular technology can then be calculated by summing all exchanges with all other technologies, so that at any given time, the total capacity for each technology can be calculated.

In this form, the model could produce outcomes that are not possible given natural resource endowments in various model regions of the world. Renewable resources, however, tend to be used in order of decreasing cost, or increasing productivity, which enables the definition of simple cost curves. These renewable cost-supply curves used are available from Mercure and Salas (2012).

Meanwhile, non-renewable resources are gradually consumed in a way which can be more dynamic. The diffusion of renewable technologies is limited in the model by costs that increase with the level of development, influencing investor choices when resources are fully developed. In the case of nonrenewable resources, a depletion algorithm is used that tracks the cost of production of fuels (oil, gas, coal and uranium) according to a path of resource consumption (Mercure and Salas, 2013).

Given an exogenous scenario of detailed electricity policy instruments (regulations, feed-in tariffs, subsidies and carbon prices), FTT:Power determines a technology mix by region. It takes electricity demand from E3MG/E3ME and feeds back a price, fuel use and investment for replacements and new generators. The feedback between FTT:Power and E3MG/E3ME is fully dynamic, such that FTT prices strongly influence demand.

FTT:Power and E3MG both model 21 world regions, allowing different policy options to be explored in different regions. Certain countries (e.g. USA, China) are explicitly treated.

From this point, having calculated the number of energy units produced using each technology in each region and given greenhouse gas (GHG) emissions associated with each technology, global GHG emissions due to electricity production can be calculated.

\section{References}

Barker T, Scrieciu S (2010) Modelling low stabilization with E3MG: towards a 'New Economics' approach to simulating energy-environment-economy system dynamics. Energy Journal, 31: 137-164.

Berglund C, Söderholm P (2006) Modeling technical change in energy system analysis: analyzing the introduction of learning-by-doing in bottom-up energy models. Energy Policy, 34(12): 1344-1356.

Cambridge Econometrics (2014) E3ME Manual, Version 6.0, Cambridge Econometrics, available online at www.e3me.com

IEA (2000) Experience Curves for Energy Technology Policy, OECD Publishing, doi: 10.1787/9789264182165-en10.1787/9789264182165-en

Mercure J-F (2012) FTT:Power : A global model of the power sector with induced technological change and natural resource depletion. Energy Policy 48: 799-811.

OECD/NEA (2010) Projected Costs of Generating Electricity 2010, OECD Publishing, doi : 10.1787/9789264084315-en10.1787/9789264084315-en 
McDonald A, Schrattenholzer L (2001) Learning rates for energy technologies. Energy Policy, 29(4): 255-261.

Mercure J-F, Salas P (2012) An assessment of global energy resource economic potentials. Energy, 46(1): 322-336. Retrieved from http://dx.doi.org/10.1016/j.energy.2012.08.018

Mercure J-F, Salas P (2013) On the global economic potentials and marginal costs of non-renewable resources and the price of energy commodities. Energy Policy, (63): 469-483. Retrieved from http://dx.doi.org/10.1016/j.enpol.2013.08.040 